\title{
A Review of 'New Explorations into International Relations: Democracy, Foreign Investment Terrorism and Conflict'
}

Published: 15 September 2016

Keywords: empirical research; foreign policy; foreign affairs; international relations (IR); negative results reporting

New Explorations into International Relations: Democracy, Foreign Investment Terrorism and Conflict Choi S-W

The University of Georgia Press: Athens, GA, USA. 2016 336 pp.; ISBN: 978-0-8203-4908-4

Author and Scholar Seug-Whan Choi's "New Explorations into International Relations: democracy, foreign investment, terrorism and conflict" serves as a nexus of interdisciplinary analysis and findings rooted in evidenced based research. Indeed, the author set out to challenge and test traditional international relations (IR) theories by implementing rigorous scientific methods in an attempt to produce policy recommendations and encourage a frameshift in methodological approaches. One underlying theme that recurs throughout this work is the requirement for rigorous statistical analysis and education in the field of political science. This has already begun and a re-emphasis is encouraged and greatly welcomed.

More specifically, the author unpacks the often used term empirical analysis, highlights some shortcomings to this methodology and then offers solutions and stopgaps to mitigate potential pitfalls in future research. Surprisingly, there is still room to describe and offer original insight into the causes and effects of civil war and social unrest, terrorism, democracy and flows of investment. This interdisciplinary approach offers cross-cutting themes to be addressed and some revolutionary ideas based on evidence. Choi is able to systematically upend some very well established political science, economic and international relations conclusions that were based on empirical study through rigorous scientific and statistical methods; leading to new findings, sometimes the opposite to those found in the original works examined. At other times they open up new territories altogether.

I think it is telling that the chapter on democratic and capitalist states and war and peace turns conventional conclusions of current security paradigms on their head. Furthermore, by challenging the paradigm of democratic institutions and policy outcomes, researchers and decision makers alike will be encouraged to apply rigorous methods to current and future policy, and most importantly the trial and error of replication study. From a methodological standpoint, this text helps show common pitfalls and relatively simple means to mitigate failure of accurate interpretation of multiple data sets of information. Choi also aptly raises the call for replication studies and null results reporting/scholarly papers, against the status quo, and encourages a permanent fixture of replication in scientific progress. A difficult feat, but greatly needed.

And if statistical analysis and rigorous scientific research methods and interdisciplinary study offer no interest to the potential reader, Choi finally unpacks general patterns of political phenomena and their attributes. In particular, the discussion on outliers pays attention to an area often overlooked and its impact on general conclusions reached in empirical study. But don't be put off by the many tables of data, statistical terminology and overall perceived headiness of this text. It is very tangible and would make ideal reading for the multidisciplinary undergraduate, graduate student, post doc and established academics alike - the need for rigorous, open and reproducible results in any discipline needs to be the mantra and battle cry of best practices and Choi makes a very good effort on this count.

Later in the text when rule or law versus democratization are discussed, another example of how data can directly relate to foreign policy (evidence and non-evidenced based) are reviewed. Discussion of civil-military relations unpack some interesting data on how it may relate to terrorism and other factors. 
Some critique may also benefit this work. Specifically, in adding to, re-analyzing and manipulating data already reported and analyzed, ethical considerations should be clearly defined. In dealing with any data sets, human related or otherwise, it is easy to have $20 / 20$ hindsight but difficult to carve ahead and be entirely unique or novel. Perhaps this work would also benefit from taking its own medicine and be reproduced in and of itself; to replicate a replication study. There will be harsh critique of some of the conclusions and findings featured in this study, but one theme cannot be attacked: statistical analysis and reproducible study are the only path to evidence based policy and must be the beacon of IR and political science study.

John M. Quinn V

Prague Center for Global Health, First Faculty of Medicine, Charles University, Prague, Czech Republic; E-Mail: john.quinn@lf1.cuni.cz 